\title{
Cognitive bias in the perception of interpersonal relations ${ }^{1}$
}

ROBERT H. RITTLE AND NICKOLAS B. COTTRELL KENT STATE UNIVERSITY

Subjects received information regarding social relationships between hypothetical persons $A$ and $B$, and then indicated the subjective probability that $A$ likes $B$, or that $A$ is influenced by $B$. Information regarding influence (and its negation) biased perception of liking relationships. Information regarding both proximity and liking (and their negations) biased perception of influence relationships.

Individuals frequently make predictions about the interpersonal relations which exist among other persons. When an individual lacks direct knowledge regarding the relations existing between two others, he is often willing to go beyond his direct knowledge in ascribing relationships to them. DeSoto \& Kuethe (1959) studied this process by giving Ss information about hypothetical people and then having them estimate the probability that one of the hypothetical people had a specific relationship to the other. The results showed that individuals display cognitive biases. When informed that $A$ likes $B$, for instance, Ss attributed a higher probability to B's liking A than when no information was provided.

Desoto \& Kuethe (1959) limited their study to situations involving just one kind of social relation. The present study examined the subjective probabilities of liking and influence relations between hypothetical people as a function of prior information about a different kind of social relation between them. Heider's (1958) discussion of interpersonal relations and the findings of studies of interacting persons (Festinger, Schachter, \& Back, 1950; Rosen, Levinger, \& Lippitt, 1961; Tagiuri \& Kogan, 1960) suggested the following hypotheses. Prior knowledge that $A$ is (is not) influenced by $B$ increases (decreases) the subjective probability that A likes B. Prior knowledge that A lives (does not live) near $B$ increases (decreases) the subjective probability that A likes B. Prior knowledge that A likes (does not like) B increases (decreases) the subjective probability that $A$ is influenced by B. Prior knowledge that A lives (does not live) near $B$ increases (decreases) the subjective probability that $A$ is influenced by $B$.

\section{Method}

The Ss were 48 male students who participated to receive credit in an introductory psychology class at Kent State University. Ss were tested in two groups of about 25 persons each.

Each $S$ received a booklet which contained the 14 items which are outlined in Table 1. The items were presented in the following basic form: "Tom lives near Jim. Is Tom influenced by Jim?"' Ss indicated the probability that $A$ had a given relationship to $B$ by circling one of the alternatives: Definitely no; Very probably no; Probably no; Chances about even; Probably yes; Very probably yes; or Definitely yes. Following the procedure of DeSoto \& Kuethe (1959), these alternatives were converted to the probabilities of $.00, .17, .34, .50, .67, .84$, or 1.00 , respectively, in quantifying the responses.

Two forms of the items were used; each form had a different, random assignment of 28 male names to the 14 items. Each of the 14 items was presented on a separate page, and the order of the pages in the experimental booklet was randomized separately for each of the Ss.

The instructions to the Ss emphasized that all of the people mentioned in the booklets knew each other in a sacial context. "Liking" was defined in the instructions as having a positive attitude toward another person; "being influenced" was defined as a willingness to follow another's advice, or to do what another requests.

\section{Resulis}

Table 1 presents the mean subjective probability that A likes B (Column 2) or that A is influenced by $B$ (Column 3) given various kinds of prior information about $A$ and $B$. Rows 4 and 6 of Table 1, involving similarity or dissimilarity of $A$ and $B$ in height, were used as baselines for assessing cognitive blases. These items are grammatically similar to the items of interest, and were assumed to convey trivial, nonbiasing information. This assumption is supported by the finding that height similarity and height dissimilarity induced almost identical subjective probabilities for both liking (Column 2 of Table 1) and influence (Column 3 of Table 1).

As predicted for the liking relationship (Column 2 of Table 1), prior information that $A$ is influenced by

Table 1. Mean Subjective Probabilities that $A$ likes $B$ or that $A$ is Influenced by $B$ as a Function of Prior Information about $A$ and $B$

\begin{tabular}{lcc} 
Prior Information & $\begin{array}{c}\text { Subjective Probabilities } \\
\text { A likes B }\end{array}$ & \begin{tabular}{c} 
A is Influenced by B \\
\hline A likes B
\end{tabular} \\
A is influenced by B & -- & .72 \\
A lives near B & .50 & -- \\
A is the same height as B & .53 & .56 \\
No prior information & .49 & .45 \\
A is not the sume height as B & .54 & .50 \\
A does not live near B & .53 & .49 \\
A is not influenced by B & .40 & .40 \\
A does not like B & -- & -- \\
\hline
\end{tabular}


$B$ increased the subjective probability that A likes $B$ (Row 2 vs $4, t=7.30, d f=47, p<.001$ ), and prior information that $A$ is not influenced by $B$ decreased the subjective probability that A likes $B$ (Row 8 vs 6 , $t=5.24$, $d f=47, p<.001)$. Contrary to prediction, prior information that $A$ lives near $B$ failed to increase the subjective probability that A likes $B$ (Row 3 vs 4 , $t=1.55, d f=47, n s$ ), and prior information that $A$ does not live near $B$ failed to decrease the subjective probability that $A$ likes $B$ (Row 7 vs $6, t=1.00$, df $=47, \mathrm{~ns})$.

As predicted for the influence relationship (Column 3 of Table 1), prior information that A likes B increased the subjective probability that $A$ is influenced by $B$ (Row 1 vs $4, t=10.45, d f=47, p<.001$ ), and prior information that $A$ does not like $B$ decreased the subjective probability that $A$ is influenced by $B$ (Row 9 vs $6, t=5.31, d f=47, p<.001$ ). Also as predicted, prior information that $A$ lives near $B$ increased the subjective probability that $A$ is influenced by $B$ (Row 3 vs $4, t=3.99$, $d f=47, p<.001$ ), and prior information that $A$ does not live near $B$ decreased the subjective probability that $A$ is influenced by $B$ (Row 7 vs $6, t=3.59$, df $=47, p<.001$ ).

\section{Discussion}

The hypotheses of the present study were inspired by findings from studies of the interdependence of social relations among interacting persons. In the present study detached observers ascribed interpersonal relations to hypothetical other persons. Six of the hypotheses were confirmed by the results of the present study. Two hypotheses were not confirmed, but the results were in the predicted direction. Thus the cognitive biases produced by verbal stimuli in the present study were similar to patterns of interpersonal relations which occur among interacting persons. These findings are consistent with Heider's (1958) contention that everyday language mirrors the verities of social experience.

\section{References}

DeSOTO, C., \& KUETHE, J. Subjective probabilities of interpersonal relations. J. abnorm. soc. Psychol., 1959, 59, 290-294.

FESTINGER, L., SCHACHTER, S., \& BACK, K. Social pressures in informal groups. New York: Harper, 1950.

HEIDER, F. The psychology of interpersonal relations. New York: John Wiley \& Sons, 1958.

ROSEN, S., LEVINGER, G., \& LIPPITT, R. Perceived sources of social power. J. abnorm. soc. Psychol, 1961, 62, 439-441.

TAGIURI, R., \& KOGAN, N. Personal preference and the attribution of influence in small groups. J. Pers., 1960, 28, 257-265.

\section{Note}

1. This research was conducted by the first author in partial fulfillment of requirements for the degree of Master of Arts at Kent State University. The research was supported in part by National Science Foundation Grant GS-1016, to the second author. Portions of the findings were presented to the Midwestern Psychological Association, Chicago, May, 1967. 